\title{
Prevalence of posttraumatic arthritis and the association with outcome measures following distal radius fractures in non-osteoporotic patients: a systematic review
}

\author{
C. M. Lameijer ${ }^{1}$ H. J. ten Duis ${ }^{1}$ I. van Dusseldorp ${ }^{2}$ P. U. Dijkstra ${ }^{3,4}$. \\ C. K. van der Sluis ${ }^{3}$
}

Received: 19 April 2017 / Published online: 2 August 2017

(C) The Author(s) 2017. This article is an open access publication

\begin{abstract}
Introduction The objective of this systematic review was to analyze (1) prevalence of radiological posttraumatic arthritis (PA), (2) associations of PA with outcome measures and (3) predictors of PA following distal radius fractures in nonosteoporotic patients.

Materials and methods Nineteen studies were included (10 open source data).

Results In total, 733 patients were described with a weighted mean age of 37 years (range 25-54) at the time of the injury. Follow-up ranged from 13 months to 38 years. Overall prevalence of PA was $50 \%$ and $37 \%$ in the open source data. Radial deviation was significantly worse in patients with PA $\left(N=49\right.$, mean $14^{\circ}, \mathrm{SD} 6^{\circ}$ versus $N=55$, mean $\left.17^{\circ}, \mathrm{SD} 6^{\circ}, p=0.037\right)$. No analysis could be performed regarding patient reported outcome measures, because of limited data. Articular incongruence was a significant predictor for PA.

Conclusions A high prevalence of PA was found in nonosteoporotic patients following a distal radius fracture. PA following a distal radial fracture was associated with
\end{abstract}

C. M. Lameijer

C.M.Lameijer@UMCG.nl

1 Department of Trauma Surgery, University Medical Center Groningen, University of Groningen, 30.001, Huispostcode BA51, 9700 RB Groningen, The Netherlands

2 Medical Center Leeuwarden, MCL Academy, Leeuwarden, The Netherlands

3 Department of Rehabilitation Medicine, University Medical Center Groningen, University of Groningen, Groningen, The Netherlands

4 Department of Oral and Maxillofacial Surgery, University Medical Center Groningen, University of Groningen, Groningen, The Netherlands a limited radial deviation and flexion, but not with grip strength. Articular incongruence predicted PA. Patient reported outcome measures should be investigated more thoroughly to be able to understand the value of using these instruments in interpreting outcome in follow-up of nonosteoporotic patients following a distal radius fracture.

Level of evidence Level of evidence 3 (Phillips et al. Levels of Evidence-Oxford Centre for Evidence-based Medicine, 1)

Keywords Wrist - Distal radius · Posttraumatic arthritis . Outcome measures

\section{Introduction}

Distal radius fractures (DRFs) are common injuries. An annual incidence of 9/10,000 men and 37/10,000 women has been reported in patients aged 35 years and older [2, 3]. In a sample of more than 87 million Americans with an upper extremity fracture in 2009, the most common fracture sites were the distal radius and ulna [4]. The incidence of DRFs is bimodal, with peak incidences in young (predominantly male) patients and older (predominantly females) patients. $[4,5]$ In young adults this type of fracture results from a high-energy trauma. In older adults, the fracture more often results from low-energy trauma $[5,6]$. It has been estimated that at 50 years of age, a woman has $16.6 \%$ remaining lifetime risk of sustaining a DRF, whereas a man has a remaining lifetime risk of just 2.9\% [7]. Prevalence of radiological posttraumatic arthritis (PA) following DRFs has been described to be as high as $65 \%$ after 6.7 years of follow-up [8]. A recent systematic review describing the development of PA suggests that presence of articular steps at the time of healing results in a higher prevalence of radiographic signs 
of PA [9]. However, the association between radiological PA and clinical outcome remains unclear. Many studies have shown that fractures healed with a step $>2 \mathrm{~mm}$ are associated with early PA [10-13]. The association between articular incongruence and PA dictates common held beliefs in the treatment of DRFs, where anatomical reduction of the articular surface and stable internal fixation are pursued.

Recent literature supports the hypothesis that increasing age is also an important risk factor for the development of PA [9]. PA is thought to develop less in younger patients. However, it might be of greater importance for this younger age group, because these patients have a long active working and sporting life ahead of them.

\section{Clinician reported outcome}

Function following a DRF can be captured using clinician reported outcomes (CROs), such as range of motion (ROM) and grip strength. PA following a DRF was associated with poorer CROs in some studies $[11,14,15]$. However, other studies did not find this association $[16,17]$.

\section{Patient reported outcome}

The patient's opinion regarding wrist function, pain or satisfaction following a DRF can be captured in Patient Reported Outcomes (PROs). A number of studies did not find a significant association between PA and PROs [10, $18,19]$. In contrast, recent literature reported a significant association between presence of PA following DRF and poorer outcomes reported on the SF-36 questionnaire in a heterogeneous age group [20, 21]. Two studies described that a higher age predicted worse PROs 1-6 years following a DRF [20, 22]. The physical component scale of the SF-36 was poorer in older patients. The mental component scale of the SF-36 was similar or even better in younger patients [20, 21, 23]. It has been suggested that patients with preexisting osteoporosis following a DRF have better scores on PROs than those without osteoporosis [21, 24]. Age and/ or preexisting osteoporosis seem to be independent factors influencing PROs following a DRF.

\section{Purpose of the study}

Conflicting results in literature have been presented on the association between outcomes and PA following DRFs. There is a need for better understanding of the clinical relevance of radiological PA following a DRF in non-osteoporotic patients. Determination of specific outcome measures predicting PA could be helpful in guiding individual treatment strategies and to decide what rehabilitation goals should be pursued in the follow-up of these patients. In addition, such outcomes could be used to prepare patients on the expected return of function and possible necessary adjustments in everyday life.

The objectives of this systematic review were to analyze (1) the prevalence of PA following a DRF, (2) associations of PA with CROs and PROs and (3) predictors of PA following a DRF in non-osteoporotic patients.

\section{Methods}

\section{Literature search}

A systematic search of the literature was performed in PubMed, Embase, the Cochrane Library and PsycINFO without time restrictions, published until January 2015. The databases were searched with a combination of MesH terms regarding PA, CROs and PROs (Table 1).

Eligible for this review were studies reporting adult patients, women between 18 and 49 years, and men between 18 and 59 years at the time of sustaining a DRF. These age selection criteria were applied to eliminate the risk of

Table 1 Search strategy in PubMed

\begin{tabular}{|c|c|}
\hline Radius fractures & ("Radius Fractures"[Mesh] OR Radius Fracture*[tiab] OR ("Radius"[Mesh] AND "Fractures, Bone"[Mesh])) \\
\hline Post-traumatic or osteoarthritis & $\begin{array}{l}\text { (post traumatic*[tiab] OR posttraumatic*[tiab] OR arthros*[tiab] OR arthrit*[tiab] OR "Joint } \\
\text { Diseases"[Mesh] OR osteoarthrit*[tiab]) }\end{array}$ \\
\hline $\begin{array}{l}\text { Functional outcome or patient } \\
\text { reported outcome or health } \\
\text { status }\end{array}$ & 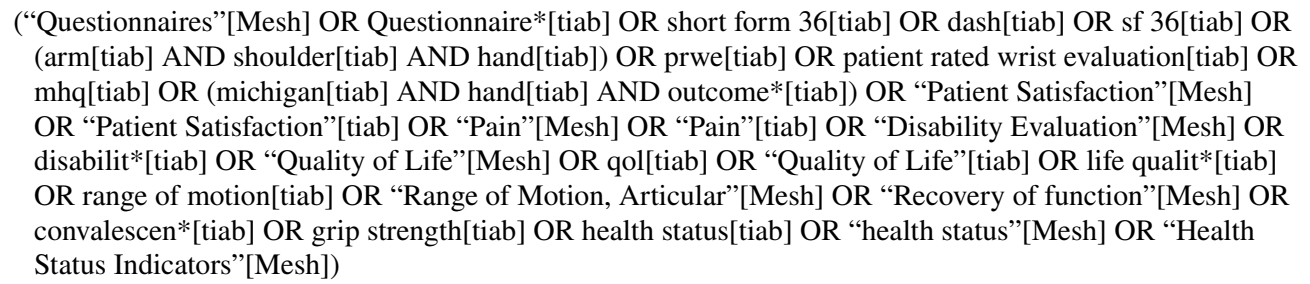 \\
\hline
\end{tabular}

Reproduction of the search strategy can be achieved through combining the different sets with the boolean operator AND. The search terms in Embase, the Cochrane Library and PsychInfo were derived from the search terms used in PubMed and are available on request from the author 
preexistent osteoporosis, because of the high prevalence of osteoporosis reported in literature in older patients, especially in postmenopausal women $[25,26]$. Furthermore, at least one of the CROs (ROM, grip strength) or PROs (Disability of Arm, Shoulder and Hand questionnaire (DASH), Patient Rated Wrist Evaluation (PRWE), Michigan Hand Questionnaire (MHQ), Short Form-36 (SF-36)) had to be described. Follow-up duration had to be at least one year after the DRF. All study designs were included. Excluded were studies with less than 5 patients and studies reporting outcome measures that integrate CROs and PROs, such as the Gartland and Werley score or the Green and O'Brien score, since separate relations of CROs or PROs with PA cannot be established from such measures [21, 27]. Studies describing open fractures were also excluded. Last, studies written in languages other than English, German or Dutch

Table 2 Newcastle-Ottawa Scale

\begin{tabular}{|c|c|c|c|}
\hline Category & Item \# & Newcastle-Ottawa Quality Assesment Scale_Cohort Studies & Points \\
\hline \multirow[t]{17}{*}{ Selection } & \multirow[t]{5}{*}{1} & Representativeness of the exposed cohort & \\
\hline & & $\begin{array}{l}\text { a. Truly representative of the average non-osteoporotic patient with a distal radius } \\
\text { fracture in the community }\end{array}$ & 1 \\
\hline & & $\begin{array}{l}\text { b. Somewhat representative of the average non-osteoporotic patient with a distal radius } \\
\text { fracture in the community }\end{array}$ & 1 \\
\hline & & c. Selected group of users, e.g. nurses or volunteers & 0 \\
\hline & & d. No description of the derivation of the cohort & 0 \\
\hline & \multirow[t]{4}{*}{2} & Selection of the non-exposed cohort & \\
\hline & & a. Drawn from the same community as the exposed cohort & 1 \\
\hline & & b. Drawn from a different source & 0 \\
\hline & & c. No description of the derivation of the non-exposed cohort & 0 \\
\hline & \multirow[t]{5}{*}{3} & Ascertainment of exposure & \\
\hline & & a. Secure record (e.g. surgical records) & 1 \\
\hline & & b. Structured interview & 1 \\
\hline & & c. Written self-report & 0 \\
\hline & & d. No description & 0 \\
\hline & \multirow[t]{3}{*}{4} & Demonstration that outcome of interest was not present at start of study & \\
\hline & & a. Yes & 1 \\
\hline & & b. No & 0 \\
\hline \multirow[t]{3}{*}{ Comparability } & \multirow[t]{3}{*}{5} & Comparability of cohorts on the basis of the design or analysis & \\
\hline & & a. Study controls for posttraumatic arthritis following a distal radius fracture & 1 \\
\hline & & $\begin{array}{l}\text { b. Study controls for any additional factor (this criteria could be modified to indicate control } \\
\text { for a second important factor) }\end{array}$ & 1 \\
\hline \multirow[t]{13}{*}{ Outcome } & \multirow[t]{5}{*}{6} & Assessment of outcome & \\
\hline & & a. Independent blind assessment & 1 \\
\hline & & b. Record linkage & 1 \\
\hline & & c. Self-report & 0 \\
\hline & & d. No description & 0 \\
\hline & \multirow[t]{3}{*}{7} & Was follow-up long enough for outcomes to occur & \\
\hline & & a. Yes (adequate follow-up for posttraumatic arthritis to occur: at least 2 years) & 1 \\
\hline & & b. No & 0 \\
\hline & \multirow[t]{5}{*}{8} & Adequacy of follow-up of cohorts & \\
\hline & & a. Complete follow-up-all subjects for at least 12 months & 1 \\
\hline & & b. Subjects lost to follow-up unlikely to introduce bias-small number lost $<10 \%$ & 1 \\
\hline & & c. Follow-up rate $>10 \%$ and no description of those lost & 0 \\
\hline & & d. No statement & 1 \\
\hline Total & & & 9 points \\
\hline
\end{tabular}

A study can be awarded a maximum of one point for each numbered item within the selection and outcome categories. A maximum of 2 points can be given for comparability 
were excluded as were articles that only comprised of a supplement or abstract for a congress.

\section{Quality assessment}

The methodological quality of the selected studies was assessed using the Newcastle-Ottawa Scale (NOS), which is initiated to evaluate the quality of non-randomized studies, such as case-control and cohort studies (Table 2) [28]. The content validity of the NOS has been established based on a critical review of the items by several experts in the field who evaluated its efficiency for assessing the quality of studies to be used in a meta-analysis [28]. With a maximum score of 9 , studies were assigned 1 point for each criterion in the checklist that was met, with the exception that 2 points can be assigned in the comparability scale (Table 2) [28]. Studies scoring $75 \%$ or more of the maximum score (i.e. $>6$ points) were considered to be of 'high quality'. Studies scoring between 50 and $75 \%$ (i.e. 5 or 6 points) were labeled 'moderate quality'. 'Low quality' was given to studies with scores lower than $50 \%$ (i.e. $<5$ points). Two reviewers scored the quality (TD, CL), difference in scoring between the two reviewers was resolved with discussion and in case of persistent disagreement a third reviewer (CS) was consulted to reach consensus.

\section{Posttraumatic arthritis assessment}

In all studies the classification for PA according to Knirk and Jupiter was applied; grade 0 represents no signs of PA and grade 3 representing bone-on-bone PA with osteophyte and cyst formation [8]. To exclude any chance of bias regarding the severity of PA as graded in the different studies, PA was computed as a dichotomous value; presence or no presence of PA.

\section{Clinician reported outcome}

Range of motion was expressed in degrees. To minimize the effect of the different units of measurement of grip strength (kilograms, kilopascal or pounds), grip strength of the injured wrist as a percentage of the uninjured wrist was calculated. No correction for dominance of hand was performed, in concordance with other studies [14, 29, 30].

\section{Patient reported outcome}

Characteristics of the PROs are described in Appendix 1.

\section{Data analysis}

Regarding reporting data from all studies, associations will be presented when reported in the studies. If associations
Fig. 1 Flowchart of the study selection

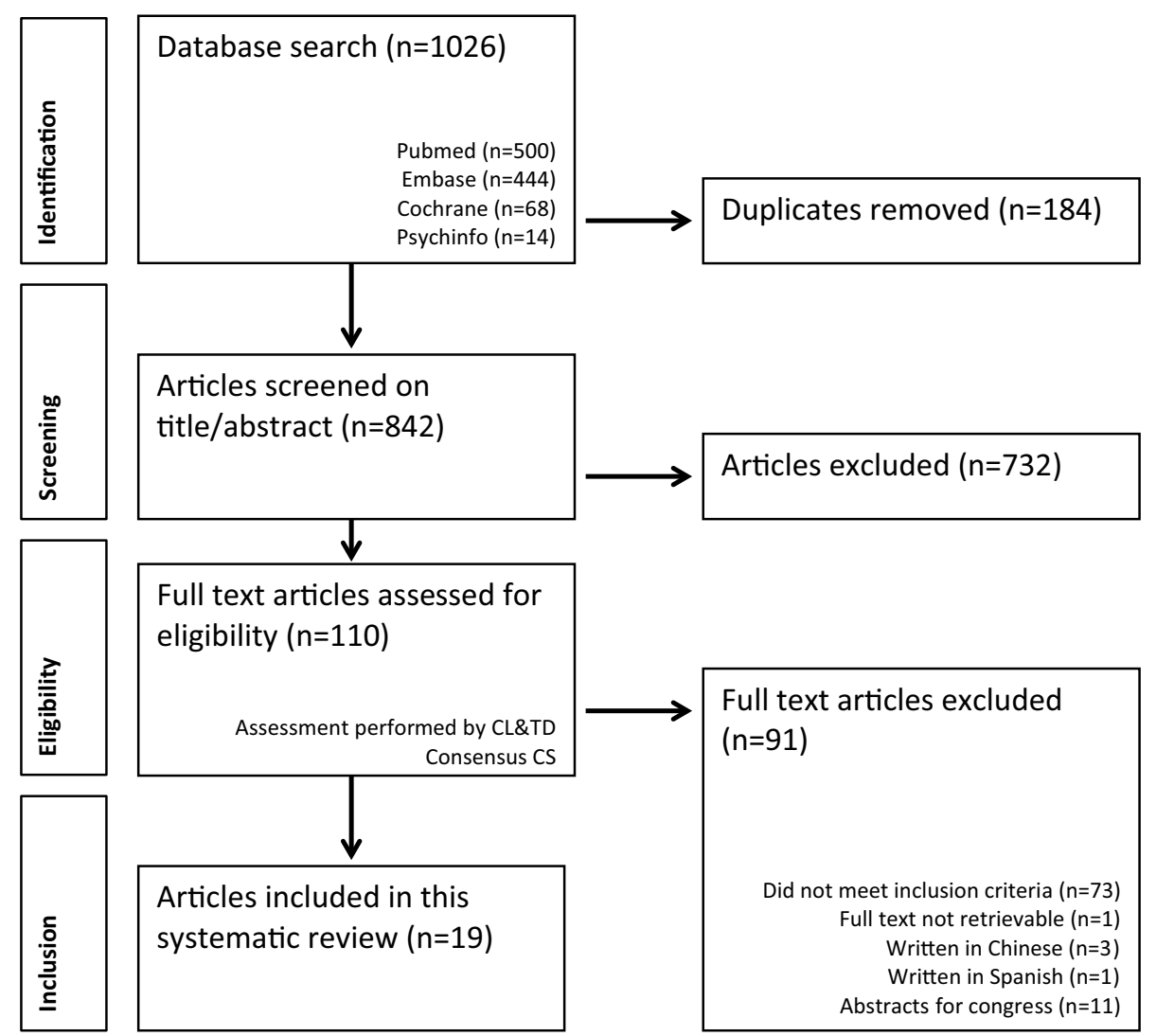




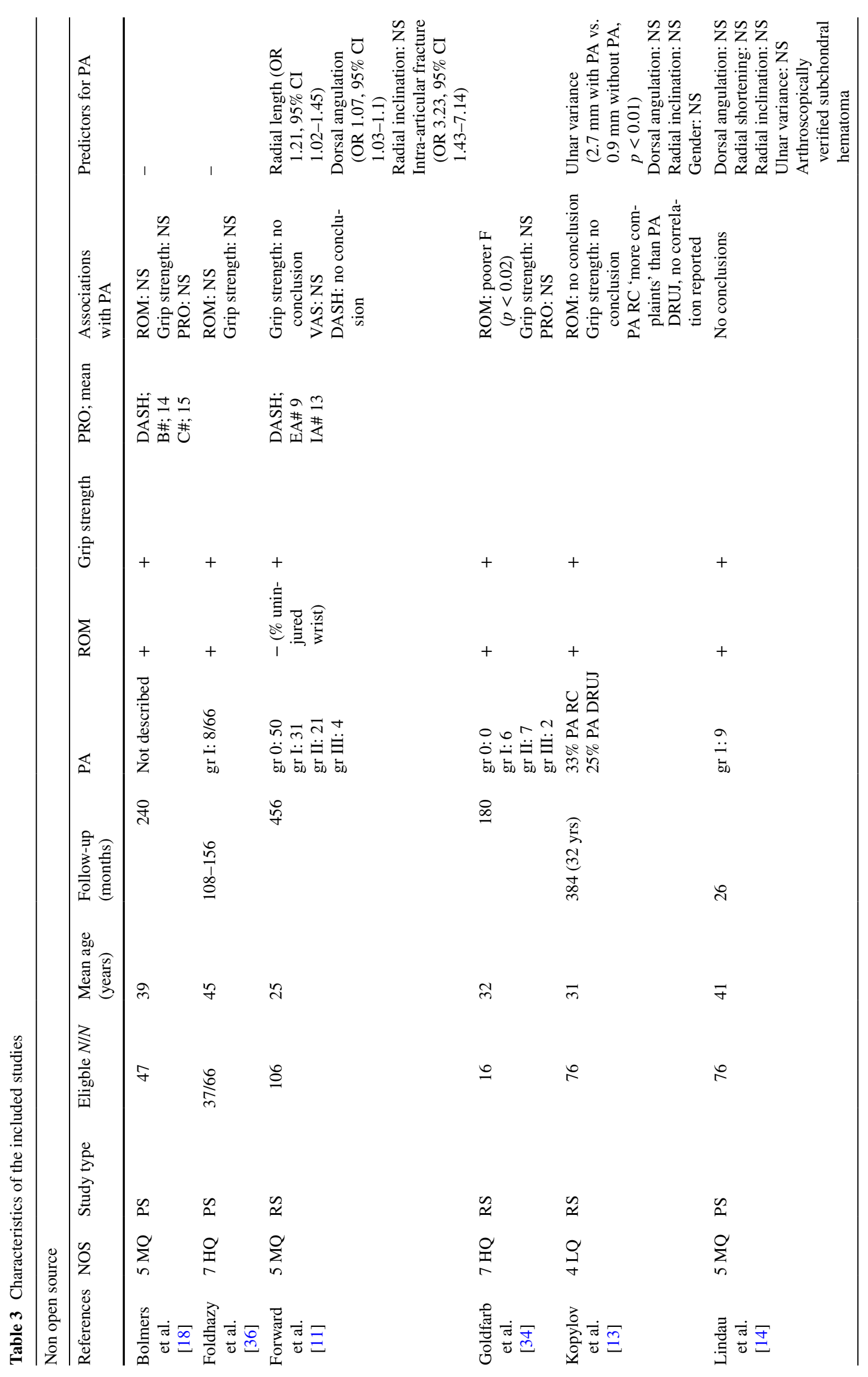




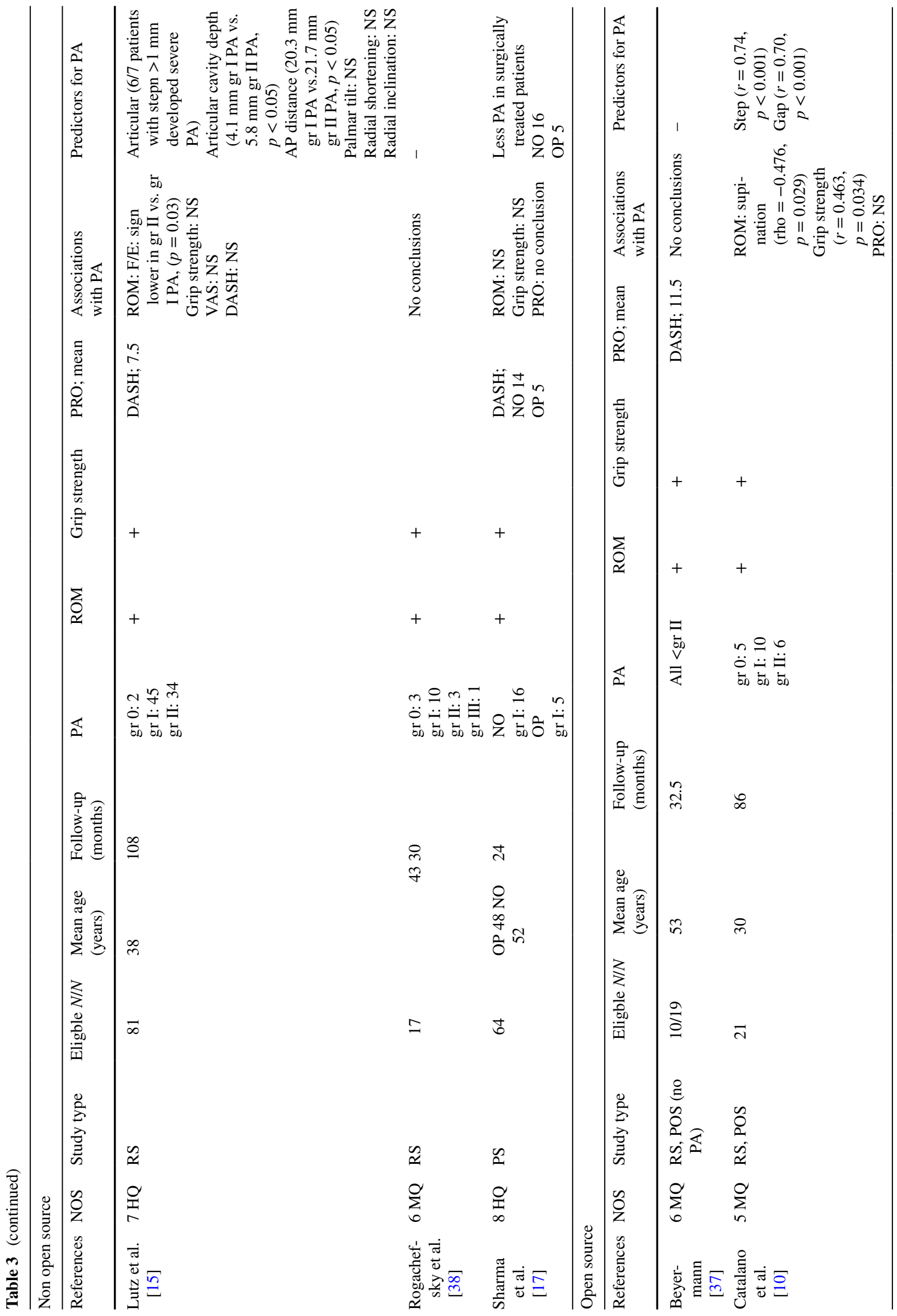




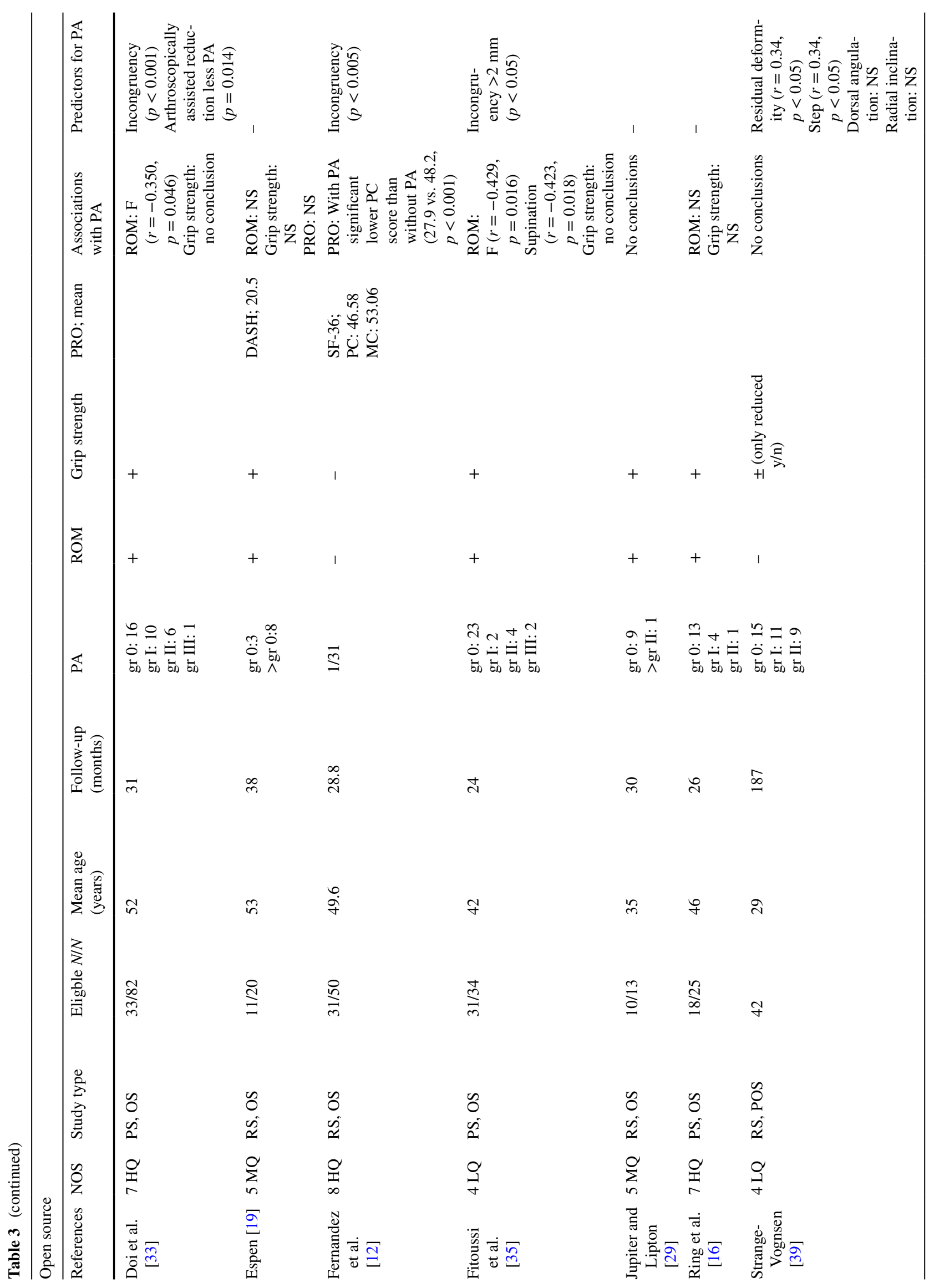




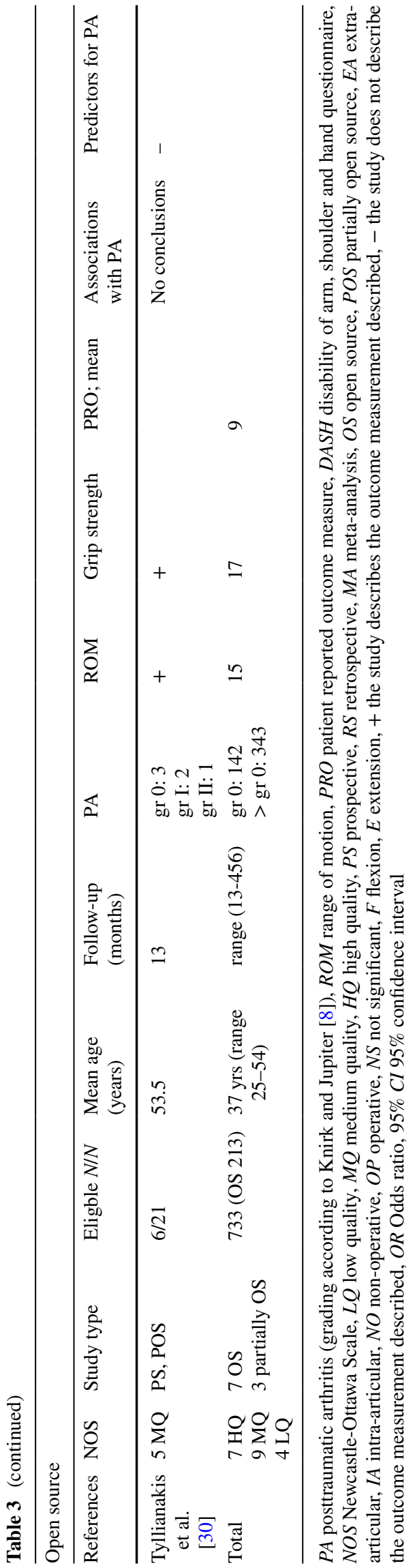

were presented using Spearman's $r$, interpretation of effect size was performed using Cohen's guideline (weak \pm 0.2 , moderate \pm 0.5 , strong \pm 0.8 ) [31]. Pooling of open source data was applied to analyze outcomes and associations. The Chi-Square test was used to analyze associations between dichotomous and/or categorical variables. $T$ test was used to analyze a dichotomous grouping variable and continuous outcome variables, normal distribution and equality in variances being present. P-plots were used to evaluate normal distribution of data and Levene's test was used to assess the equality of variances. If there was no normal distribution of data and/or no equality in variances, Mann-Whitney $U$ analysis was performed and medians and interquartile ranges (IQR) were presented. In the statistical analysis of the open source data, PA was transformed to a dichotomous variable (presence or no presence of PA). Significance was achieved when $p<0.05$. All statistical analyses were performed using IBM SPSS, version 22.

\section{Results}

\section{Study selection}

The study selection was performed in three stages. First, one reviewer (CL) retrieved 1026 articles from the patient database with the help of an information specialist. All studies where imported in RefWorks ${ }^{\circledR}$. After removing duplicates, a total of 842 studies remained. Second, two reviewers (CL and TD) assessed independently titles and abstracts. A total of 110 papers remained. The same reviewers assessed the full text papers. In case of persistent disagreement a third reviewer (CS) was consulted to reach consensus. Reasons for exclusion were; not retrievable $(n=1)$, written in Chinese language $(n=3)$, written in Spanish $(n=1)$, supplements or abstracts for a congress $(n=11)$ and not meeting the inclusion criteria $(n=73)$. Twenty studies met the inclusion criteria, of which two of the selected publications were conducted by the same research group and described the same patient population $[14,32]$. Therefore one of these studies was excluded, resulting in 19 included studies (Fig. 1) [32]. If this was presented in the studies, open source data was collected.

\section{Study and patient characteristics}

\section{All studies}

The study populations of the included studies ranged from 13 to 106 patients. Eight prospective and 11 retrospective cohort studies were included. A total of 733 patients were described with a weighted mean age of 37 years (range 
25-54) at time of the injury. Follow-up ranged from 13 months to 38 years (Table 3). The weighted prevalence of PA was $50 \%$ (343 of 683 patients). Seven studies were classified as high quality, nine as moderate quality and 3 of low quality according to the NOS quality assessment (Table 3) [28].

\section{Open source}

Ten studies comprised of open source data of 213 patients (169 men) with a median age of 37 years (IQR 27; 44) and median follow-up of 31 months (IQR 24; 73) (Table 4). The classification of the fracture type was described in 161 patients, with the majority having an AO/OTA type $\mathrm{C} 3$ fracture $(n=74)$. The weighted overall prevalence of PA was $37 \%$. Prevalence of PA after a follow-up of $\leq 36$ months (range $12.5-36$ months) was $31 \%$. This was statistically significantly lower than the prevalence of PA $(64 \%, p<0.001)$ after a follow-up of $>36$ months (range 36-192 months).

\section{Association between PA and CRO: range of motion}

\section{All studies}

Three out of the 16 studies describing ROM, reported a statistically significant association between the presence of PA and diminished flexion (Table 3) [33-35]. Two of these three studies described moderate statistical significant associations $(r=0.350, p=0.046$ and $r=0.429$, $p=0.016$, respectively) $[33,35]$. One study described a statistically significant lower ROM in flexion-extension arc in patients with PA grade II compared to patients with grade I PA [15]. A moderate statistically significant association between PA and poorer supination was found in one study ( $r=-0.476, p=0.029$ ) [10]. Five studies did not find a statistically significant association between PA and ROM. [16-19, 36] In the six remaining studies the association between PA and ROM was not analysed [14, 29, 30, 37-39].

\section{Open source}

Of the 10 studies with (partially) open source data, seven had data regarding ROM (Table 3) [10, 16, 19, 29, 33, 35, 37]. Pooled data analysis is presented in Table 5. Radial deviation was statistically significantly worse in the patients with PA $\left(N=49\right.$, mean $\left.14^{\circ}, \mathrm{SD} 6^{\circ}\right)$ compared to patients without PA $\left(N=55\right.$, mean $\left.17^{\circ}, \mathrm{SD} 6^{\circ}, p=0.037\right)$. All other outcomes regarding range of motion in the patients with and without PA did not differ with statistical significance (Table 5).

\section{Association between PA and CRO: grip strength}

\section{All studies}

One out of the 18 studies describing grip strength found a moderate statistically significant association between severity of PA and diminished grip strength $(r=0.464$, $p=0.034$ ) [10]. In contrast, seven studies did not find a significant association [15-19, 34, 36]. The remaining 10 studies did not analyse the association between PA and grip strength.

\section{Open source}

Eight studies presented open data regarding grip strength (Table 3) [10, 16, 19, 29, 30, 33, 35, 37]. No statistically significant association between PA and grip strength was found (Table 5).

\section{Association between PA and PROs}

PROs were reported in few studies (Table 3). It was decided not to report nor perform statistical analysis on these limited results.

\section{Predictors of PA}

\section{All studies}

Eleven studies reported on predictors of PA following a DRF (Table 3). Articular incongruence (step and/or gap) at follow-up was found to be a statistically significant predictor of PA in six studies [10, 12, 15, 33, 35, 39]. The weights of the associations were described as strong and moderate in two of these 11 studies (step $r=0.74$, $p<0.001$ and gap $r=0.70, p<0.001$; step $r=0.34$, $p<0.05$, respectively) [10,39]. Conflicting results on other predictive radiological factors, such as shortened radial length, dorsal angulation, radial inclination, ulnar variance and AP distance, were reported (Table 3) [11, 14, 39, 40]. In a longitudinal study a significant progression of PA after a longer follow-up duration was found (15 vs. 7 years, $p=0.02$ ) [34]. Older age at the time of injury was associated with earlier development of PA [11]. Gender was not associated with the development of PA [13]. One study described PA to be statistically significantly less often present in patients treated surgically compared to patients treated conservatively [17]. Another study reported less PA when arthroscopically assisted surgical treatment was performed compared to non-arthroscopically assisted surgical treatment [33]. 
Table 4 Patient characteristics from the open source data

\begin{tabular}{|c|c|c|c|c|c|}
\hline \multirow[t]{2}{*}{ Characteristics } & \multirow{2}{*}{$\begin{array}{l}\mathrm{PA}(N=79) \\
\mathrm{N} / \text { median }(\mathrm{IQR})\end{array}$} & \multirow{2}{*}{$\begin{array}{l}\text { No PA }(N=117) \\
\text { N/median }(\mathrm{IQR})\end{array}$} & \multicolumn{2}{|l|}{$\begin{array}{l}\text { Total population } \\
(N=213)\end{array}$} & \multirow[t]{2}{*}{ Significance } \\
\hline & & & N/median (IQR) & $\%$ & \\
\hline \multicolumn{6}{|l|}{ Age (years) } \\
\hline$N$ & 79 & 117 & 213 & & NS \\
\hline Median & 36 years $(27-44)$ & 37 years $(27-44)$ & 37 yrs (27-44) & & \\
\hline \multicolumn{6}{|l|}{ Gender } \\
\hline Male & 64 & 92 & 169 & 79 & NS \\
\hline Female & 15 & 24 & 44 & 21 & \\
\hline \multicolumn{6}{|l|}{ Follow-up (months) } \\
\hline$N$ & & & 193 & & $p=0.026$ \\
\hline Median & $\begin{array}{l}46 \text { months } \\
(24-100)\end{array}$ & $\begin{array}{l}28 \text { months } \\
(24-37)\end{array}$ & $\begin{array}{l}31 \text { months } \\
(24-73)\end{array}$ & & \\
\hline \multicolumn{6}{|l|}{ Trauma energy } \\
\hline Low energy & 7 & 4 & 15 & 21 & NS \\
\hline High energy & 30 & 25 & 58 & 79 & \\
\hline \multicolumn{6}{|c|}{$\mathrm{AO} / \mathrm{OTA}$ fracture classification } \\
\hline A & 3 & 11 & 11 & 6.4 & NS \\
\hline B & 56 & 10 & 13 & 7.6 & \\
\hline $\mathrm{C}$ & 59 & 81 & 147 & 86 & \\
\hline \multicolumn{6}{|l|}{ Treatment } \\
\hline Non-operative & 18 & 14 & 38 & 18 & $p=0.047$ \\
\hline Surgery & 61 & 102 & 174 & 82 & \\
\hline \multicolumn{6}{|c|}{ Articular incongruence at follow-up (step and/or gap) } \\
\hline No & 8 & 58 & 66 & $48 \%$ & $p<0.001$ \\
\hline Yes & 51 & 20 & 71 & $52 \%$ & \\
\hline Step $(\mathrm{mm})$ median & $1.0 \mathrm{~mm}(1.0-2.0)$ & $0.0 \mathrm{~mm}(0.0-1.0)$ & $1.0 \mathrm{~mm}(0.0-1.7)$ & & $p<0.001$ \\
\hline No & 9 & 25 & 34 & 39 & \\
\hline Yes & 44 & 10 & 54 & 51 & \\
\hline Gap $(\mathrm{mm})$ median & $0.0 \mathrm{~mm}(0.0-1.0)$ & $0.0 \mathrm{~mm}(0.0-0.0)$ & $0.0 \mathrm{~mm}(0.0-1.0)$ & & $p=0.017$ \\
\hline No & 20 & 19 & 39 & & \\
\hline Yes & 13 & 2 & 15 & & \\
\hline \multicolumn{6}{|c|}{ Grading PA according to Knirk and Jupiter } \\
\hline Gr 0 & & 84 & 84 & 55 & \\
\hline Gr I & 39 & & 39 & 25 & \\
\hline Gr II & 28 & & 28 & 18 & \\
\hline Gr III & 3 & & 3 & 2 & \\
\hline
\end{tabular}

$I Q R$ interquartile range, $P A$ posttraumatic arthritis, $N S$ not significant, $\mathrm{mm}$ millimeter

\section{Open source}

At a median follow-up of 31 months (IQR 24; 73) $52 \%$ of the patients had some kind of articular incongruence (step and/ or gap). Patients with PA experienced statistically significant more often residual articular incongruence in comparison to patients without PA (51 versus 20 patients, $p<0.001$ ). Furthermore, patients with PA experienced statistically significant more often a residual step (44 versus 10 patients, $p<0.001$ ) or gap (13 versus 2 patients, $p=0.017$ ) (Table 4$)$.
Follow-up was statistically significant longer in the patients who did develop PA (median 46 months (IQR 24; 100) versus median 28 months (IQR 24; 37), $p=0.026$ ). All possible radiological predictors directly after fracture reduction and at the end of follow-up were not significantly associated with PA (Table 6).

Age at the time of injury did not differ statistically significantly between patients with and without PA (Table 3). Gender was not associated with the presence of PA. No statistical analysis on the influence of intra- versus extra-articular 
Table 5 Open source data regarding ROM and grip strength

\begin{tabular}{|c|c|c|c|c|c|c|c|c|}
\hline \multicolumn{2}{|l|}{ Range of motion } & \multicolumn{3}{|l|}{ PA } & \multicolumn{3}{|l|}{ No PA } & \multirow[t]{2}{*}{ Significance } \\
\hline & $N$ & Mean $\left(^{\circ}\right)$ & SD & $N$ & Mean $\left(^{\circ}\right)$ & SD & $N$ & \\
\hline Flexion & 124 & 52 & 18 & 55 & 52 & 16 & 69 & NS \\
\hline Extension & 124 & 53 & 13 & 55 & 54 & 11 & 69 & NS \\
\hline Arc motion F/E & 124 & 105 & 26 & 55 & 107 & 23 & 69 & NS \\
\hline Ulnar deviation & 104 & 23 & 9 & 49 & 25 & 8 & 55 & NS \\
\hline Radial deviation & 104 & 14 & 6 & 49 & 17 & 6 & 55 & $p=0.037$ \\
\hline Arc motion UD/RD & 104 & 37 & 12 & 49 & 42 & 11 & 55 & $p=0.063$ \\
\hline Pronation & 124 & 76 & 14 & 55 & 75 & 12 & 69 & NS \\
\hline Supination & 124 & 76 & 15 & 55 & 81 & 19 & 69 & NS \\
\hline \multicolumn{2}{|l|}{ Grip strength } & \multicolumn{3}{|l|}{ PA } & \multicolumn{3}{|l|}{ No PA } & \multirow[t]{2}{*}{ Significance } \\
\hline & $N$ & Mean (\%) & SD & & Mean (\%) & SD & $N$ & \\
\hline$\%$ Grip strength & 124 & 79 & 18 & 55 & 79 & 15 & 69 & NS \\
\hline
\end{tabular}

$S D$ standard deviation, $P A$ posttraumatic arthritis, $N S$ not significant, $F / E$ dorsal flexion/extension, $U D / R D$ ulnar deviation/radial deviation, ${ }^{\circ}$ degrees, $\%$ percentage

Table 6 Open source data regarding predicting radiological factors for PA

\begin{tabular}{|c|c|c|c|c|c|c|c|c|}
\hline \multirow[t]{2}{*}{ Radiological measurement } & \multirow[t]{2}{*}{$N$} & \multicolumn{3}{|l|}{ PA } & \multicolumn{3}{|l|}{ No PA } & \multirow[t]{2}{*}{ Significance } \\
\hline & & Mean & SD & $N$ & Mean & SD & $N$ & \\
\hline \multicolumn{9}{|l|}{ Dorsal angulation $\left({ }^{\circ}\right)$} \\
\hline Postreduction & 31 & 1 & 7.6 & 8 & -3.3 & 9.4 & 23 & NS \\
\hline Follow-up & 149 & -1.3 & 10.2 & 58 & -2.7 & 9.3 & 91 & NS \\
\hline \multicolumn{9}{|l|}{ Radial length (mm) } \\
\hline Postreduction & 33 & 10.1 & 5.2 & 8 & 9.9 & 3.7 & 23 & NS \\
\hline Follow-up & 81 & 10.6 & 3.9 & 25 & 10.8 & 3.6 & 56 & NS \\
\hline \multicolumn{9}{|l|}{ Ulnar variance (mm) } \\
\hline Postreduction & 27 & 1.4 & 2.1 & 7 & -0.2 & 2.0 & 20 & NS \\
\hline Follow-up & 98 & 1.0 & 2.3 & 45 & 0.9 & 2.3 & 53 & NS \\
\hline \multicolumn{9}{|l|}{ Radial inclination $\left({ }^{\circ}\right)$} \\
\hline Postreduction & 31 & 21.3 & 8.9 & 8 & 19.7 & 5.7 & 23 & NS \\
\hline Follow-up & 148 & 21.5 & 5.1 & 57 & 21.2 & 4.7 & 91 & NS \\
\hline
\end{tabular}

$S D$ standard deviation, $P A$ posttraumatic arthritis, $N S$ not significant, ${ }^{\circ}$ degrees, $\%$ percentage fracture types on PA could be performed, because only 11 patients with an extra-articular fracture were described. In the patients with intra-articular fractures, no significant difference in the development of PA was seen between $\mathrm{AO} /$ OTA type $\mathrm{B}$ and $\mathrm{C}$ fractures or between AO/OTA type $\mathrm{C} 1$, $\mathrm{C} 2$ or $\mathrm{C} 3$ fractures (Table 4 ).

\section{Discussion}

A high prevalence of the development of PA following a DRF in non-osteoporotic patients was found $(50 \%$ in all patients with a range in follow-up duration of 13 months to 38 years, $37 \%$ in the open source studies after a median follow-up of 31 months). In addition, this study shows that the prevalence of PA seems to worsen over time (respectively, $31 \%$ after a follow-up of $0-36$ months versus $64 \%$ follow-up duration after 36 months). Presence of PA was statistically significantly associated with diminished radial deviation and flexion, but not with grip strength. Unfortunately, no conclusions could be drawn regarding the association between PA and PROs, because of lack of data. An intra-articular step or gap had a statistical significant negative effect on the development of PA. No further associations between radiological predictors and PA were found using open source data. Operative treatment or arthroscopically assisted surgical treatment seemed to reduce the chance of developing PA [17, 33]. 


\section{Prevalence of PA}

The high prevalence of PA in this non-osteoporotic population is worrisome. However, from the included studies we could not derive sufficient information on the restrictions or limitations these patients experienced when executing activities of daily living, leisure time activities, work or other societal roles. Further research on PA in non-osteoporotic patients with DRF should elaborate on the impact of PA on patients' activities or participation. Since most studies comprise of small study populations and because the open source data showed that a longer follow-up duration is associated with a higher prevalence of PA, specifically open source studies may provide unique chances to gather such data. However, currently no uniform set of evaluation instruments is available, which results in difficulty of pooling data.

\section{Association between PA and CROs}

Wrist motion is dependent on complex articulations of the scaphoid, lunate and the radio carpal joint [41]. Biomechanically, flexion-extension and radio-ulnar deviation are a result of motion of the scaphoid and lunate in respect to the distal radius, which relies on the ligamentous stability between these two carpal bones and movement in the adjacent joint surfaces [42]. The majority of the DRFs in non-osteoporotic patients result from high-energy trauma and, therefore frequently are intra-articular fractures. It is imaginable that the direction of the intra-articular force associated with this type of fracture causes intercarpal ligamentous injury as well as joint surface changes. Recent literature describes an incidence of $38 \%$ of associated scapholunate (SL) or lunotriquetral (LT) ligamentous injuries in distal radius fractures. [43] Associated SL or TL ligamentous injuries could be an explanation for the limited radial deviation and flexion and early PA as described in this systematic review. Furthermore, malalignment of the distal radius following a fracture can cause alterations of the distal radio-ulnar joint with anatomical change of the radio-ulnar contact area, resulting in limited pronation and supination [44]. Based on the results of this systematic review, it can be concluded that grip strength does not seem to be influenced by PA. This emphasizes that grip strength might not be an important determinant of wrist function and is not one of the first symptoms of PA, but merely a reflection of overall muscle strength and condition [45]. Ageing is typically associated with a progressive loss of skeletal muscle mass and occurs at a rate of 3-8\% each decade after the age of 30 years $[46,47]$. Although age is a confounding factor for grip strength, our results indicate that in this relatively young group of patients grip strength is not influenced to a significant extent by age. A recent Cochrane reported on different rehabilitation methods following distal radius fractures in adults was published [48]. Twenty-six trials were included which turned out to be inhomogeneous with regards to patient characteristics (i.e. age) and were qualified as low or very low quality evidence. The authors therefore concluded that available evidence is insufficient to establish the relative effectiveness of different rehabilitation methods. It is suggested by the authors to precede rehabilitation research regarding outcome in patients with distal radius fractures with a clear aim [48]. From our systematic review it is suggested that rehabilitation in non-osteoporotic patients with distal radius fractures should have a broad approach, with special focus on wrist motion (radial deviation and flexion). Although we did not find an association between grip strength and radiological PA, it is still an important determinant of total outcome and should be addressed appropriately in rehabilitation treatment.

\section{Associations between PA and PROs}

No conclusions could be drawn regarding the association between PA and PROs, because of limited data. This is indicative of a gap in knowledge on the clinical relevance of radiological PA as measured by PROs, despite the high prevalence of PA in this group.

\section{Predictive factors for PA}

A high prevalence of PA was shown, and a longer follow-up duration was associated with a higher prevalence of PA. As such, development of PA seems to be a dynamic process and progresses over time. In addition, articular incongruence was predictive for PA: patients with a step or a gap had a higher prevalence of PA. This outcome resembles the conclusions drawn in studies regarding associations between articular incongruence and PA following a DRF [10-13]. When articular incongruence is associated with the development of PA, it might be assumed that the AO/OTA classification of the fracture type would also have an association with PA. This association was not found in this study. The reason no statistical significant differences were found between $\mathrm{AO} /$ OTA type B and C fractures regarding the development of PA could be that inter- and intraobserver variability of the AO/OTA classification of distal radius fractures has been reported to be moderate to poor [49]. Another explanation could be that the DRFs have been surgically treated if a large incongruence was present and only the residual deformity or articular incongruence will affect the development of PA. It is hypothesized that with surgical treatment (with or without direct arthroscopic control), better anatomical reduction of the articular surface can be achieved and, therefore may diminish the chance of developing PA [17, 33]. Conflicting results regarding several radiological measurements predicting PA were presented in literature. However, analysis of our open source data suggests that dorsal angulation, radial 
length, ulnar variance and radial inclination do not predict $\mathrm{PA}$. These conflicting results on predicting radiological factors could be due to a substantial variability in how these factors are defined in literature. It has been suggested to develop guidelines to ensure consistency when interpreting different radiographic measurements reported in literature [50].

\section{Strength and weaknesses}

This study is the first systematic review presenting CROs and PROs and the association with PA following DRFs in non-osteoporotic patients. Because of the extent of this systematic review and the pooling of the open source data, we believe this study is a contribution to the insight in the prevalence and clinical relevance of PA in non-osteoporotic patients following a DRF. Recent literature has encouraged pooling of open source data from clinical trials and cohort studies and reporting this in systematic reviews and metaanalyses to compare outcome in a more reliable and efficient manner [51, 52]. Although we believe pooling of the open source data in this systematic review contributes to the strength of the conclusions, variability between raters and the way measurements have been performed, should be acknowledged. Some other limitations of our systematic review should be acknowledged. We have chosen an age selection criteria (men 18-59 years, women $18-49$ years) to eliminate the risk of preexisting osteoporosis. Despite our selection criteria, some of the included patients may still have had osteoporosis. All studies included in this systematic review were cohort studies or case-control studies (level of evidence II and III) with relatively small populations and moderate methodological quality [53]. These restrictions should be taken into account when interpreting the results of this meta-analysis. In general, research in the field of rehabilitation and injuries should be more transparent by presenting open source data, especially when describing small populations, to be able to compare data in a reliable way. In addition, despite our extensive literature search, very limited data was retrieved regarding PROs. We decided not to report on these limited results and, therefore no conclusions could be drawn regarding PROs following DRFs in non-osteoporotic patients. Furthermore, a new scoring method was used to assess the methodological quality of the studies, with equal weights for each quality category, except for the comparability category [28]. It could be argued that the quality categories should be scored separately instead of a combined total score to provide optimal insight into the quality of the different studies. Most included studies reported statistical significance of their results, but the weight of the associations was poorly described. Several authors have described associations between the residual articular incongruence and PA.

\section{Further research}

The high prevalence rate of PA found in the (pooled open source) data shows that investigation of outcome in nonosteoporotic patients with a long active and working life ahead should have more attention. To direct treatment strategy, rehabilitation and to decide what an acceptable level of rehabilitation is in the follow-up of non-osteoporotic patients with a DRF there is a need for a reliable interpretation of PROs and the association with PA investigated by using randomized controlled trials with or without implementing pooling of open source data. For patients and therapists it would be of great value to be able to work towards an evidence-based rehabilitation goal. It would also be very beneficial to gain more insight in the influence of radiological characteristics following fracture reduction, such as radial shortening and radial inclination on CROs, PROs and PA.

\section{Conclusions}

Half of all non-osteoporotic patients developed some degree of PA following a DRF. In addition, PA seems to progress over time. PA following a distal radial fracture was associated with a limited radial deviation and flexion, but not with grip strength. This suggests that rehabilitation should have a broad approach, with focus on wrist motion, and on learning to adjust daily activities to limited wrist motion to optimize functional recovery. Unfortunately no conclusions could be drawn regarding PROs and their clinical applicability in the follow-up of DRF in non-osteoporotic patients, because of limited data. PROs should be investigated more thoroughly to be able to understand the value of using these instruments in interpreting outcome in follow-up of these non-osteoporotic patients. Further research could produce evidence-based rehabilitation goals for patients and therapists. Treatment of DRF should be directed at avoiding articular incongruence, because of its statistically significant association with the development of PA. Conflicting results in literature have been reported on dorsal angulation, radial length, ulnar variance and radial inclination on predicting PA. More thorough research on other radiological factors predicting PA could show more insight on primary treatment goals to avoid PA in the follow-up of these young non-osteoporotic patients.

Acknowledgements We would like to thank dr. J.J. Fernandez for his kind cooperation with supplying additional raw data from his research. In addition to the nine other studies presenting open source data, this allowed us to pool more raw data to perform statistical analysis on.

\section{Compliance with ethical standards}

Conflict of interest All authors declare that they have no conflict of interest. 
Funding There is no funding source.

Ethical approval This article does not contain any studies with human participants or animals performed by any of the authors.

Open Access This article is distributed under the terms of the Creative Commons Attribution 4.0 International License (http://creativecommons.org/licenses/by/4.0/), which permits unrestricted use, distribution, and reproduction in any medium, provided you give appropriate credit to the original author(s) and the source, provide a link to the Creative Commons license, and indicate if changes were made.

\section{Appendix 1. Specific characteristics of PROs}

DASH. The Disability of Arm Shoulder Hand questionnaire is a 30-item self-report measure focusing on physical functioning and symptoms of the upper limb. DASH scores range from 0 to 100 (higher scores indicate worse function).

PRWE. The Patient Rated Wrist Evaluation assesses pain and functioning in patients with wrist fractures [54]. The PRWE includes 5 items assessing pain, which are rated from 0 (no pain) to 10 (unbearable pain) and 10 items assessing function [36]. The function subscale is divided into two sections concerning specific activities and usual activities. For each section the maximum score is 50 (most disability) and the minimum score is 0 (no disability). A higher score indicates a worse outcome. The questionnaire has a fair validity for symptoms and function of the wrist.

MHQ. The Michigan Hand Outcomes Questionnaire is a validated questionnaire assessing hand outcomes that are of importance to patients and specific for the impaired hand (left and right separately). It includes 6 domains (overall hand function, activities of daily living, pain, work performance, aesthetics and satisfaction). A higher score indicates a better function of the impaired wrist [55].

SF-36. The Short Form-36 questionnaire is developed to survey overall health status [56]. It uses 36 items to asses limitations in (1) physical function, (2) role function, (3) social function, (4) bodily pain, (5) general mental health, (6) limitations in role function due to emotional problems, (7) vitality and (8) general health perception. A physical and a mental component summary score can be calculated. A higher score indicates a better quality of life as experienced by the patient.

\section{References}

1. Phillips B, Ball C, Sackett D, Badenoch D, Straus S, Haynes B et al (2009) Levels of evidence. Oxford Centre for Evidence-based Medicine, Oxford

2. O'Neill TW, Cooper C, Finn JD, Lunt M, Purdie D, Reid DM et al (2001) Incidence of distal forearm fracture in British men and women. Osteoporos Int 12(7):555-558
3. Staa TP, Geusens P, Zhang B, Leufkens HG, Boonen A, Cooper $C$ (2007) Individual fracture risk and the cost-effectiveness of bisphosphonates in patients using oral glucocorticoids (Structured abstract). Rheumatology 46(3):460-466

4. Karl JW, Olson PR, Rosenwasser MP (2015) The Epidemiology of Upper Extremity Fractures in the United States, 2009. J Orthop Trauma 29(8):e242-e244

5. MacIntyre NJ, Dewan N (2016) Epidemiology of distal radius fractures and factors predicting risk and prognosis. $\mathrm{J}$ Hand Ther 29(2):136-145

6. Handoll Helen HG, Huntley James S, Madhok R (2008) Different methods of external fixation for treating distal radial fractures in adults. The Cochrane Library

7. van Staa TP, Dennison EM, Leufkens HG, Cooper C (2001) Epidemiology of fractures in England and Wales. Bone 29(6):517-522

8. Knirk JL, Jupiter JB (1986) Intra-articular fractures of the distal end of the radius in young adults. J Bone Joint Surg Am 68(5):647-659

9. Giannoudis PV, Tzioupis C, Papathanassopoulos A, Obakponovwe O, Roberts C (2010) Articular step-off and risk of posttraumatic osteoarthritis. Evidence today. Injury 41(10):986-995

10. Catalano LW III, Cole RJ, Gelberman RH, Evanoff BA, Gilula LA, Borrelli J Jr (1997) Displaced intra-articular fractures of the distal aspect of the radius: long-term results in young adults after open reduction and internal fixation. J Bone Jt Surg Ser A 79(9):1290-1302

11. Forward DP, Davis TR, Sithole JS (2008) Do young patients with malunited fractures of the distal radius inevitably develop symptomatic post-traumatic osteoarthritis? J Bone Jt Surg Br 90(5):629-637

12. Fernandez JJ, Gruen GS, Herndon JH (1997) Outcome of distal radius fractures using the short form 36 health survey. Clin Orthop Relat Res 341:36-41

13. Kopylov P, Johnell O, Redlund-Johnell I, Bengner U (1993) Fractures of the distal end of the radius in young adults: a 30-year follow-up. J Hand Surg Br 18(1):45-49

14. Lindau T, Hagberg L, Adlercreutz C, Jonsson K, Aspenberg P (2000) Distal radioulnar instability is an independent worsening factor in distal radial fractures. Clin Orthop Relat Res 376:229-235

15. Lutz M, Arora R, Krappinger D, Wambacher M, Rieger M, Pechlaner S (2011) Arthritis predicting factors in distal intraarticular radius fractures. Arch Orthop Trauma Surg 131(8):1121-1126

16. Ring D, Prommersberger K, Jupiter JB (2004) Combined dorsal and volar plate fixation of complex fractures of the distal part of the radius. J Bone Joint Surg Am 86-A(8):1646-1652

17. Sharma H, Khare GN, Singh S, Ramaswamy AG, Kumaraswamy V, Singh AK (2014) Outcomes and complications of fractures of distal radius ( $\mathrm{AO}$ type $\mathrm{B}$ and $\mathrm{C}$ ): volar plating versus nonoperative treatment. J Orthop Sci 19(4):537-544

18. Bolmers A, Luiten WE, Doornberg JN, Brouwer KM, Goslings JC, Ring D et al (2013) A comparison of the long-term outcome of partial articular (AO Type B) and complete articular (AO Type C) distal radius fractures. J Hand Surg (USA) 38(4):753-759

19. Espen D (2003) Combined palmar and dorsal approach for complex distal radius fractures. Handchir Mikrochir Plast Chir 35(1):22-30

20. Gruber G, Zacherl M, Giessauf C, Glehr M, Fuerst F, Liebmann W et al (2010) Quality of life after volar plate fixation of articular fractures of the distal part of the radius. J Bone Jt Surg Am 92(5):1170-1178

21. Van Son MA, De Vries J, Roukema JA, Den Oudsten BL (2013) Health status and (health-related) quality of life during the recovery of distal radius fractures: a systematic review. Qual Life Res 22(9):2399-2416 
22. MacDermid JC, Richards RS, Roth JH (2001) Distal radius fracture: a prospective outcome study of 275 patients. J Hand Ther 14(2):154-159

23. MacDermid JC, Donner A, Richards RS, Roth JH (2002) Patient versus injury factors as predictors of pain and disability six months after a distal radius fracture. J Clin Epidemiol 55(9):849-854

24. Nordvall H, Glanberg-Persson G, Lysholm J (2007) Are distal radius fractures due to fragility or to falls? A consecutive casecontrol study of bone mineral density, tendency to fall, risk factors for osteoporosis, and health-related quality of life. Acta Orthop 78(2):271-277

25. Harvey N, Dennison E, Cooper C (2010) Osteoporosis: impact on health and economics. Nat Rev Rheumatol 6(2):99-105

26. Cauley JA (2013) Public health impact of osteoporosis. J Gerontol A Biol Sci Med Sci 68(10):1243-1251

27. Jaremko JL, Lambert RG, Rowe BH, Johnson JA, Majumdar SR (2007) Do radiographic indices of distal radius fracture reduction predict outcomes in older adults receiving conservative treatment? Clin Radiol 62(1):65-72

28. Wells G, Brodsky L, O'Connol D, Shea B, Henry D, Tugwell P (2015) Manual Newcastle-Ottowa Scale

29. Jupiter JB, Lipton H (1993) The operative treatment of intraarticular fractures of the distal radius. Clin Orthop Relat Res 292:48-61

30. Tyllianakis M, Mylonas S, Saridis A, Kallivokas A, Kouzelis A, Megas P (2010) Treatment of unstable distal radius fractures with Ilizarov circular, nonbridging external fixator. Injury 41(3):306-311

31. Cohen J (1988) Statistical power analysis for the behavioral sciences. Routledge, New York

32. Lindau T, Adlercreutz C, Aspenberg P (2003) Cartilage injuries in distal radial fractures. Acta Orthop Scand 74(3):327-331

33. Doi K, Hattori Y, Otsuka K, Abe Y, Yamamoto H (1999) Intraarticular fractures of the distal aspect of the radius: arthroscopically assisted reduction compared with open reduction and internal fixation. J Bone Joint Surg Am 81(8):1093-1110

34. Goldfarb CA, Rudzki JR, Catalano LW, Hughes M, Borrelli J Jr (2006) Fifteen-year outcome of displaced intra-articular fractures of the distal radius. J Hand Surg Am 31(4):633-639

35. Fitoussi F, Ip WY, Chow SP (1997) Treatment of displaced intraarticular fractures of the distal end of the radius with plates. $\mathrm{J}$ Bone Jt Surg Ser A 79(9):1303-1312

36. Foldhazy Z, Tornkvist H, Elmstedt E, Andersson G, Hagsten B, Ahrengart L (2007) Long-term outcome of nonsurgically treated distal radius fractures. J Hand Surg Am 32(9):1374-1384

37. Beyermann K (2000) Prommersberger K-. Reconstruction of comminuted distal radius fractures using a combined dorsal and palmar approach. Handchir Mikrochir Plast Chir 32(6):404-410

38. Rogachefsky RA, Lipson SR, Applegate B, Ouellette EA, Savenor AM, McAuliffe JA (2001) Treatment of severely comminuted intra-articular fractures of the distal end of the radius by open reduction and combined internal and external fixation. J Bone Joint Surg Am 83-A(4):509-519

39. Strange-Vognsen H (1991) Intraarticular fractures of the distal end of the radius in young adults: a 16 (2-26) year follow-up of 42 patients. Acta Orthop Scand 62(6):527-530
40. Kwok IH, Leung F, Yuen G (2011) Assessing results after distal radius fracture treatment: a comparison of objective and subjective tools. Geriatr Orthop Surg Rehabil 2(4):155-160

41. Crisco JJ, Coburn JC, Moore DC, Akelman E, Weiss AP, Wolfe SW (2005) In vivo radiocarpal kinematics and the dart thrower's motion. J Bone Joint Surg Am 87(12):2729-2740

42. Stromps JP, Eschweiler J, Knobe M, Rennekampff HO, Radermacher K, Pallua N (2015) Impact of scapholunate dissociation on human wrist kinematics. J Hand Surg Eur. doi: $10.1177 / 1753193415600669$

43. Kasapinova K, Kamiloski V (2015) Influence of associated lesions of the intrinsic ligaments on distal radius fractures outcome. Arch Orthop Trauma Surg 135(6):831-838

44. Prommersberger KJ, Lanz U (1999) Biomechanical aspects of malunited distal radius fracture. A review of the literature. Handchir Mikrochir Plast Chir 31(4):221-226

45. Leong DP, Teo KK, Rangarajan S, Lopez-Jaramillo P, Avezum A Jr, Orlandini A et al (2015) Prognostic value of grip strength: findings from the Prospective Urban Rural Epidemiology (PURE) study. Lancet 386(9990):266-273

46. Arvandi M, Strasser B, Meisinger C, Volaklis K, Gothe RM, Siebert $\mathrm{U}$ et al (2016) Gender differences in the association between grip strength and mortality in older adults: results from the KORA-age study. BMC Geriatr 16(1):201

47. Roubenoff R, Castaneda C (2001) Sarcopenia-understanding the dynamics of aging muscle. JAMA 286(10):1230-1231

48. Handoll HH, Elliott J (2015) Rehabilitation for distal radial fractures in adults. Cochrane Database Syst Rev Sep 25(9):CD003324

49. Ploegmakers JJW, Mader K, Pennig D, Verheyen CCPM (2007) Four distal radial fracture classification systems tested amongst a large panel of Dutch trauma surgeons. Injury 38(11):1268-1272

50. Lalone EA, Grewal R, King GJ, MacDermid JC (2015) A structured review addressing the use of radiographic measures of alignment and the definition of acceptability in patients with distal radius fractures. Hand (NY) 10(4):621-638

51. Bashir R, Dunn AG (2016) Systematic review protocol assessing the processes for linking clinical trial registries and their published results. BMJ Open 6(10):e013048

52. Doiron D, Burton P, Marcon Y, Gaye A, Wolffenbuttel BH, Perola $M$ et al (2013) Data harmonization and federated analysis of population-based studies: the BioSHaRE project. Emerg Themes Epidemiol 10(1):12

53. Evans D (2003) Hierarchy of evidence: a framework for ranking evidence evaluating healthcare interventions. J Clin Nurs 12(1):77-84

54. MacDermid JC, Turgeon T, Richards RS, Beadle M, Roth JH (1998) Patient rating of wrist pain and disability: a reliable and valid measurement tool. J Orthop Trauma 12(8):577-586

55. Shauver MJ, Chung KC (2013) The Michigan hand outcomes questionnaire after 15 years of field trial. Plast Reconstr Surg 131(5):779e-787e

56. Ware JE, Kosinski M (2001) Interpreting SF-36 summary health measures: a response. Qual Life Res 10(5):405-413 (discussion 415-20) 